\title{
TOWARDS A DEBATE ON THE POSITIONING OF ENGINEERING DESIGN
}

\author{
McMahon, Chris (1); \\ Eckert, Claudia (2); \\ Fadel, Georges (3) \\ 1: University of Bristol; \\ 2: The Open University; \\ 3: Clemson University
}

\begin{abstract}
This paper is an invitation to a debate on the positioning of engineering design as a field of research. The paper lists a multiplicity of interpretations of design, questioning whether they are sufficient to describe engineering design in all its variety. Following a critical analysis of attempts to describe design's unique characteristics, and observations on the nature of design made from outside of the design research community, it presents a list of situations of design that the authors have observed in engineering practice, describing especially the relationship between design, technology and society. The paper then explores what these situations imply about the questions researchers should ask about the nature of design knowledge and expertise, and examines how the different situations might be categorised, before exploring the positioning of engineering design research with respect to other academic disciplines, in particular management and the human and earth sciences. The paper concludes with a call to a debate on the nature of engineering design with the aim to define this field more clearly to ourselves and to others.
\end{abstract}

Keywords: Design practice, Design theory, Technology

\section{Contact:}

McMahon, Christopher

University of Bristol

Department of Mechanical Engineering

United Kingdom

chris.mcmahon@bris.ac.uk

Cite this article: McMahon, C., Eckert, C., Fadel, G. (2021) 'Towards a Debate on the Positioning of Engineering Design', in Proceedings of the International Conference on Engineering Design (ICED21), Gothenburg, Sweden, 16-20 August 2021. DOI:10.1017/pds.2021.578 


\section{INTRODUCTION}

The artificial world is created through design (Simon, 1996). In a highly technological world, engineering design has an enormously important role to play. Given this importance, it is perhaps surprising that a clear understanding of its place and of its complexity by its practitioners and by other disciplines is not well established, and that there is not more debate about its nature, in particular as both design and engineering are widely discussed concepts. This raises the question of how engineering design research can position itself with regard to other fields and whether the academic understanding and public perception of engineering design adequately reflect what may be found in practice. This paper is a position paper by the authors, based on decades of research on engineering practice, tools and methods. It does not claim to be comprehensive, rather it aims to foster a debate on the specific role and characteristics of engineering design and how it may be positioned to get the prominence it deserves.

A number of characteristics of design and of design processes and thinking have been identified in the research literature. However, much of this has addressed design from the perspective of $a b$ initio design, often user centred and/or where the understanding or framing of the problem coevolves with the solution, and often presents the view that design is a creative process and necessarily involves novelty (Cross, 1982) (Hatchuel and Weil, 2009). While this can also apply to engineering design, this paper looks at the topic from a different perspective. Much engineering design is incremental, where technical innovation and adaptation come together to address societal challenges or market opportunities in a holistic, and at the same time efficient way. Engineering design needs to synthesize the insights from many different fields. The research community also needs to position itself with respect to those fields.

The rest of this paper first presents a short overview, in section 2, of work aiming to define the nature of design, which is helpful, but perhaps misses what the authors believe are some of the fundamental aspects of engineering design. Section 3 presents reflections on the challenge of characterising engineering design together with observations from outside the engineering design community. It concludes by presenting a (necessarily incomplete) list of different recurring situations found in engineering design that might form a starting point for reflection on how well these situations are explained and supported by research to date, not individually, but holistically. Suggestions are then made about what these situations may require in terms of design knowledge and expertise, and the way they may be categorised is examined. Next, section 4 considers the positioning of engineering design research with respect to other academic disciplines, emphasising its role in the development of science and technology. Finally, in section 5, suggestions are made for questions to be debated in the engineering design community on the nature and positioning of engineering design and design research.

\section{DESCRIPTIONS OF DESIGN?}

Is it possible to identify what it is that distinguishes design from other human endeavours? A number of authors have tried, with a focus ranging from the professional designer to design as an everyday activity. With an emphasis on the former, design is presented as a decision-making process (Hazelrigg, 1998), that it involves optimisation, that designers "generate, evaluate, and specify concepts" (Dym et al., 2005), that modelling is the language of the designer (Andreasen, 1994), and that its central concern is "the conception and realisation of new things" (Cross, 1982). With a broader focus, design is conceptualised as a rational problem-solving process (Simon, 1996). It is argued that across all fields of design there are particular and distinctive "designerly ways of knowing" (Cross, 1982), which can be identified and taught. The notion of 'design thinking' has also recently attracted a great deal of attention (Brown, 2008).

Design is also seen as pervasive: "everyone designs who devises courses of action aimed at changing existing situations into preferred ones" (Simon, 1996), and it is postulated that design has many similarities between the different domains in which it is applied "[the] design process in engineering is not different in principle from that in architecture or fashion or music. It is a form of composition, of expression, and as such is open to all the creativity we associate with these" (Arthur, 2009). These views, although true in specific aspects of the design process, however underemphasise the influence that scale, complexity, technical challenge, division of labour and understanding of specific technologies have on many engineering design processes. The different proponents assert their 
definitions with vigour, but how compatible are these views - that 'everyone designs' and yet there are particular 'designerly ways of knowing'?

As design permeates many aspects of the artificial world, individual researchers approach design from different angles and perspectives, addressing problems in different fields and at different scales. It is therefore not surprising that design is characterised in different ways. The perspectives of industrial design and computer system design have a strong emphasis on the user. The focus of a universal field of applications in 'design thinking' is pushed by business schools and consultants. Emphasis on design as decision-making, focusing on ways to support decisions when considering multiple objectives and possibly multiple decision makers, has the hallmarks of the mathematician's search for rigour, as does an emphasis on optimisation. Does the emphasis on 'clean sheet of paper' design perhaps come from the academic's search for approaches that are teachable to those with little industrial experience?

There is also the issue that design research tends to concentrate on the study of phenomena that are amenable to study using tractable research methods. For example, studying design through protocol analyses of relatively brief design activities undertaken by lone designers or small groups is very much more straightforward to arrange than the study of the design of a commercial aircraft or automobile, taking many years, involving thousands of participants and cloaked in issues of commercial confidentiality. Yet, the understanding of the latter is of enormous importance. In mapping out the breadth of the design landscape it is therefore important to be aware that the perspective of researchers and teachers may orient research towards what can be studied through experiments or small-scale case studies, and the specific characteristics of the highly complex, incremental and interconnected engineering issues for which industry requires support may be missed. Furthermore, like other complex phenomena, design can only be probed. It may only be possible to get a partial, incomplete view, and the full context with all its influences can never be captured fully. As in the study of history, understanding is often limited to narratives and vignettes.

\section{THE DIVERSE AND INCREMENTAL NATURE OF ENGINEERING DESIGN}

Engineering design is a very broad discipline that spans levels of detail and scale, one that adapts to various challenges and that enables the practitioner to consider the impact of the artefact on the user, the environment and society while understanding and attempting to control most of its operational and interaction aspects. To embrace the richness of engineering design it is necessary to expand on the 'original-adaptive-variant' of the engineers Pahl and Beitz (1984), or Pugh's notion of conceptually static and dynamic design (Pugh, 1991) and to identify the range of different problem and solution types found in practice. Especially it is important to understand much better what is meant by 'adaptive', and the variety of activities that may be seen in this and in 'original design'. The differences between the activities are typically the result of problems of different sizes, of the nature of the constraints applied to the problem, of the pace and direction of technological change, of the complexity of the artefact, of the current emphasis or interest in society (sustainable design for instance) and of many other issues such as regulatory prescriptions, and ability to prototype. Understanding and explaining such differences will require the development of a rich characterisation of engineering activities, which could then be tested by applying to it to different situations and by mapping methods and tools. Only then will it be possible to ascertain when and where important research contributions such as design for additive manufacture, robust design or design thinking are most likely to be helpful.

\subsection{External perspectives on engineering design}

In considering the positioning of engineering design, it may also be helpful to explore how observers looking from outside the discipline view the subject. The economist Brian Arthur uses the term "standard engineering" for the generation of a new artefact by putting together methods and elements under "principles that are known and accepted" - e.g. a new bridge or a new aircraft using established technologies (Arthur, 2009). Historian Edward Constant, in his study of the historical origins of the turbojet revolution, uses the term "normal engineering" in a similar context, drawing an analogy with the 'normal science' of Kuhn's 'The Structure of Scientific Revolutions' (Constant, 1980) (Kuhn, 1962). Kuhn suggested that most scientists address themselves to narrow 'problems' within the context of established scientific frameworks or paradigms (e.g. Newtonian mechanics). In a similar way, Constant contends that most engineers address themselves to developments within the context of established engineering frameworks or ways of doing things. Arthur's 'standard' seems to imply the importance of 
understanding well-established practices and principles, while Constant's 'normal' implies the concentration on particular patterns which are only reluctantly discarded. Under what circumstances does a paradigm shift occur in engineering in which radical alternative approaches are adopted?

Engineering design has the technical skills to create and understand products at all level of detail while maintaining a view of the whole life cycle context. Engineers are trained to decompose a problem and address sub-problems then bring the whole back together to solve the overall problem. In car design, different engineers work on chassis structure, suspension, engine, cabin, electronic controls, software, infotainment systems etc., in broadly well understood ways, and all these have to be brought together ultimately to produce the vehicle. However, as Simon (1969) points out, there are limits to the decomposability of complex (engineering) systems, so that the interaction between the different elements will need to be considered carefully, as non-linear behaviours are likely to be displayed. The increase in complexity of products, and especially their interdisciplinarity, has highlighted the need to better understand and deal with integration aspects between multiple systems, mechanical and electrical for instance, or the user and the artefact, or also between the various components themselves. Very often some particular issue will dominate the engineering considerations in a field. Historian of technology Hughes (1993), from his study of the early design and development of electrical networks, suggested that as development progresses, engineers encounter certain constraints that are particularly challenging, often of a technical nature, and that need a sustained and concentrated effort to resolve. Hughes characterised engineering progress as temporally punctuated by such concentrated effort which he compared with military progress to eliminate 'reverse salients'.

There may also be useful perspectives from the management literature. For example, Maister's (1993) work on managing the professional service firm distinguishes between three categories of professional work - (1) procedural work, for which the solution/approach is well known, and which can be delegated to less experienced staff, and where the required approaches are codified to a significant extent; (2) 'grey hair' work, which is based on the experience of the professional and of his or her firm in some particular application, and (3), 'grey matter' (i.e. 'brain work'), work that requires a good deal of intellectual effort and expertise, because it is novel for the firm. The first two categories correspond in design to cases where some code of practice or similar approach is used, or where the designer uses experience gained with previous similar problems, often adapting some previous design. The third case is where the situation has not been encountered before, and would correspond to original design. Example design situations.

As an illustration of what the mapping that we describe might involve, let us consider some diverse examples of different design situations for which we might ask "how well does the research community understand and support design in such a situation?". The list was generated through a brainstorming activity by the authors, where they looked for design situations related to industrial practice that might challenge the various design paradigms described earlier. Which of these might be found on a similar list drawn up by industrial designers? The list is necessarily narrow and incomplete, and has overlapping entries at different hierarchical levels, but our point is that the research community might seek to develop, expand and structure the list in order to examine how well each situation has been researched and is explained by the theoretical understanding of design, and to signal to governments and industry the sort of directions in which research support is lacking, essential, or desired.

1. Design of an artefact by bringing together available 'standard' elements under principles that are known and accepted and with no change in the technologies of the elements or of the resulting artefact. Into this category might be put much building design, design of tooling for manufacture, most bespoke machine design and so on. This is, in the US terms for mechanical engineers, the "Shigley approach" (Shigley, 1963), or what is more traditionally taught in most universities as machine design. Note also that kinematic design, hydraulic systems design and thermal systems design often fit this pattern. In fact, this approach is the dimensioning approach to mechanical design using standard elements, screws, shafts, beams, motors, linkages, pumps, pipes, etc.

2. Design of the 'next generation' of an artefact, in which the technical trajectory and maintenance of the state of the art are important, but in which there is no change in the fundamental technology of the resulting artefact. Such design takes advantage of technical developments by part and sub-system suppliers, in modelling tools and so on. Examples include the routine design of motor vehicles, ships and many other artefacts. Some have seen drastic evolutions in their designs over the years, but regulatory and legal concerns push engineers to work with suppliers, modelling tools and possibly hardware-in-the-loop approaches to support decision making and 
result in a 'next generation' design that is generally technologically close to the existing artefact.

3. Design of the 'next generation' of an artefact, in which there is some major technological development at some sub-system level. An example of such is in the replacement of the internal combustion engine by electric drives in motor vehicles, the move to the use of heat pumps for space heating in houses, or redesign to exploit the new possibilities offered by a novel material or manufacturing technology, for example through additive manufacture or use of composite materials.

4. Sub-categories of (2) and (3) include feasibility studies, technology demonstrators and the like.

5. Design of an artefact in which allocation of a limited resource (typically space or weight) is a critical consideration. French calls this disposition (French, 1971), but it is also found in many packaging challenges such as the design of a smart phone (space constraints) a nuclear submarine (packaging power system, crew quarters and equipment into a tube) or a satellite (size and weight constraints), and is often found as an activity within design situations (1) to (3). Packaging considerations highlight the need to address multidisciplinary problems since bringing together many components must not only address placement and lack of interference, but also consideration of thermal, vibrational and electromagnetic issues among others. Furthermore, tight packaging often challenges the designer to identify ways to assemble and possibly disassemble products to, for instance, enable maintainability.

6. Design of an artefact in which a key issue is the matching of sub-parts to each other - for example matching the compressor and turbine of a gas turbine engine, or matching the various components of the drive train of a hybrid car (again often found as an activity within situations (1) to (3)).

7. Design of the architecture of a platform to support a product family, in applications ranging from razors to commercial aircraft. Issues include how is the platform architecture planned for the product evolution and for the ability to maximize commonality while providing the ability to diversify and address multiple needs.

8. Design within the context of a platform, in which the designed artefact has to conform to the platform's 'rules' - for example designing apps for use on a smart phone or design of hand tools that all use the same rechargeable battery type or design of multiple vehicle variants that are all built on the same chassis such as the GM skateboard-style electric vehicle platform

9. Design of artefacts which evolve through their life cycles, for example by re-configuration by the user, by through-life technology insertion, or through multiple releases, as is the case for many computing artefacts.

10. Multi-disciplinary design such as the design of cyber-physical and mechatronic systems, increasingly also incorporating advanced computing techniques such as machine learning.

11. Design that involves engaging with and exploitation of large volumes of data, such as for example infrastructure design that involves understanding the impact of loading from the natural environment over many years, or design of devices that will be used in vast numbers, such as drone swarms.

12. Design of systems in which design takes places at many levels from whole system to component, and in which the artefact is partly designed, partly evolved (De Weck et al., 2011). An example of such designs is the design of a transportation system, for instance trains, track, stations, etc.

13. Design to minimise impact: through deep understanding of the impacts of the artefact on the environment, considering the life-cycle of the product as well as the entire energy, material and information chain. For example, designing an electric vehicle must take into consideration charging stations, electrical production, distribution, batteries, storage, etc.

14. Design in which consideration of the user is dominant, for example industrial design or affordance-based design that considers the interaction between the user and the artefact and how different users perceive what they can do with the artefact.

15. Original design leading to a new technology. Original design addresses either a known need in a new way, or spurs a new need. One approach to such design is that of an artefact that creates a new technology through the novel combination of existing technologies, such as for example the design of the Sony Walkman or the first Apple iPhone.

16. A second approach to original design leading to a new technology is one that brings a newly identified technological phenomenon into useful operation as a new technology. Examples include the early incorporation of magnetrons into radar equipment, or the packaging of LEDs such that they may be used in commercially useful lamps. 
For each of these situations (and there will be many more), it is suggested that the community might explore how well the descriptions of design given in sections 2 and 3, and in what combination, explain what may be observed in practice, and how well those descriptions explain the variety of situations that may be observed. Furthermore, what is the method and tool support needed for each of these situations, what are the appropriate processes and tools that enable design in such contexts and how well have they already been delivered by the research community? For academics, how well is each situation supported by teaching material? For years, situation 1 has been taught in engineering curricula. It is still critical to teach this material today although new technologies such as additive manufacturing have enabled engineers to come up with solutions that may not be solved using traditional machine design approaches. Researchers have addressed or attempted to address most of the situations described above, but how completely, and how well has this understanding been developed into an integrated and holistic approach that may lead to teachable material and to a recognized and respected field in engineering?

\subsection{Deepening understanding of engineering design practice}

To develop a better understanding of these situations, and to develop tools and methods to address them, a better and more detailed understanding of design practice and the theory and concepts that underpin it may be needed.

In terms of theory, for example, consider domain theory, which regards the designer as working in three domains (Andreasen et al., 2014):

- the activity domain, which focuses on how the artefact is used, including the product's lifecycle,

- the organ domain, which focuses on what the artefact is able to do - how the functional elements interact to create the required effects for the artefact,

- the part domain, which focuses on the artefact's parts, how they relate to each other and how the artefact is made in a manufacturing or construction process.

Different design cases might be distinguished according to the domains in which the design activity takes place. For the design of many engineered artefacts - the ones that Pugh calls 'conceptually static' - the dominant engineering work is in the part domain. How the product is used is well known, as are the main 'organs', i.e. the overall architecture, that achieve the desired functions. As another instance, much 'design for X' - for example design for assembly or design for additive manufacture may also apply largely in the part domain. If there is substitution of technologies within the artefact, or if there is functional extension (e.g. adding of emissions control equipment to a ship) then both the organ and part domains are in play, while even very routine design of a building, or of automation equipment in a factory, would be likely to involve all three domains.

Another theoretical perspective is the distinction between working by developing the underpinning scientific and engineering understanding of an artefact and working in a more conceptual way. CK Theory distinguishes in this regard between 'science-based products' and 'creativity-based products' (Hatchuel, 2003). They quote the example of a combustor for a Mars mission as a science-based product, showing how CK informs a research programme to support the design but also provides a theoretical basis for a reframing of the design task. For the contrasting creativity-based product - a holder for nails while using a hammer - the theory guides the exploration of the conceptual C-space for the artefact. These are only two theoretical views among many. The authors advocate a continuation of the categorisation and evaluation of these, for example building on the anthology in Chakrabarti and Blessing (2016), testing the explanatory value of theories against an extended list of design situations such as that begun above.

There may also be a need to examine the nature of knowledge and expertise in design to reflect both the diversity of design challenges and the increasing integration of different engineering disciplines. The relevant contextual knowledge needs to be analysed to transfer this understanding to different fields of engineering or different technologies. For example, how portable are skills in 'packaging' in different technological domains? Could a skilled car designer move to the design of ships or locomotives or to the design of a spacecraft or machine tool, and what would they need to find out in the new field? A more differentiated picture of different engineering practices also enables a clearer definition of the scope of different methods and the development of versions of the methods that work in specific contexts, as opposed to the multiple separate developments (see Gericke et al., 2020)).

All of this implies a development in research methods, for example more ethnographic studies and more studies with embedded researchers of the sort carried out by Bucciarelli (1994) and Badke- 
Schaub (1999) as well as carefully conducted and reported case studies. Because of the challenges of commercial confidentiality (and the consequent constraints on publication), it may imply more use of historic records, more retrospective qualitative studies with practitioners, of the sort carried out by historians and management researchers. It also implies less reliance on study of students and others working on artificial problems.

To gain a better understanding of engineering design practice, and to continue to establish the fundamentals of a field or science of design, engineering design research may also need to more clearly position itself. The following section describes what the authors believe might be considered and we suggest that the design research community also engages in a debate to consider this positioning of engineering design research.

\section{POSITIONING DESIGN RESEARCH}

Engineering design research needs to not only draw on the knowledge of different disciplines, engineering design itself needs to integrate the knowledge and solutions from many different fields in the artefacts it designs and the processes it uses to do so.

\subsection{Engineering design in the context of other disciplines}

Pahl and Beitz (1984) showed engineering design at the intersection of two streams from politics to art and from science to production (Figure 1). Going back nearly 50 years in its origins, this diagram substantially predates the rise of computer technology and data science in engineering, which now would feature prominently. It is our perception that in recent years the public understanding of design has been focused strongly towards the 'lower' part of the cross, towards industrial design and applied art, and that a refocussing towards the centre is needed. A government report on the future of the UK's Design Council, also citing the European Commission, felt it necessary to say explicitly that design is "a broad discipline concerned with more than just aesthetics" (Temple, 2010). A greater understanding in the broader community of the roles of technology, sciences and economics in design, and especially of the knowledge embedded in artefacts and their development history, will allow actions and developments in the sciences (especially the engineering sciences), in economics and management and in production to be better understood and guided. This has implications for the way in which research is carried out, and for a better alignment between research communities.

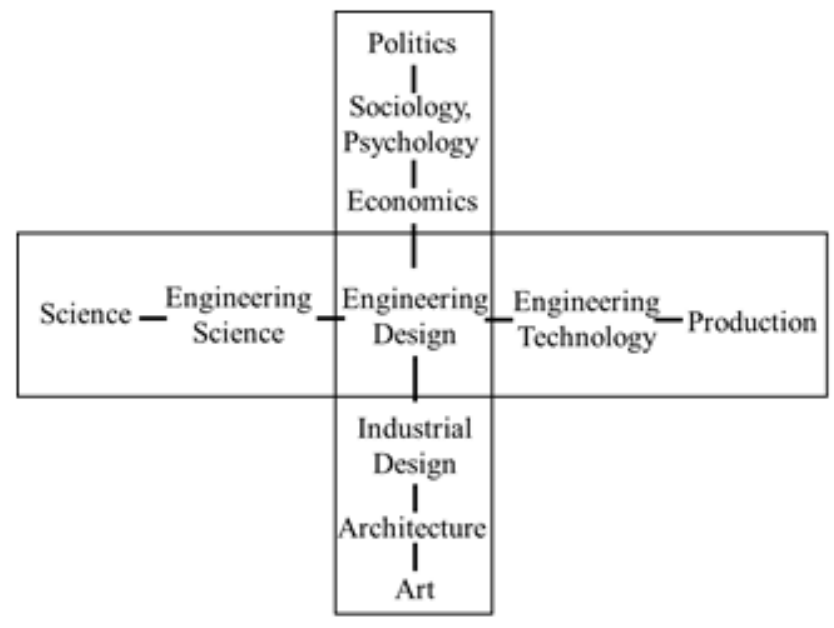

Figure 1. Design at the intersection (Pahl and Beitz, 1984)

Today's artefacts are increasingly interlinked and interconnected. We live in an era of engineering systems, that are partly designed, partly evolved (De Weck 2011). Engineering design needs to be understood in this context, in the necessary interdisciplinarity, in the enormous number of interconnections that may be at play. Again, this implies the need for research to understand the nature of design in this context, and to build on the strong links established in recent years between engineering design and systems researchers (for example the current writing of the Handbook of Engineering Systems Design with which many colleagues are involved).

Figure 2 shows an alternative model, where engineering design is a central integrating factor for the knowledge of other disciplines. In the development of any product, engineering design uses 
technologies and methodologies supported by different scientific fields (inner white ring). In the selection and application of these technologies and solution elements engineering design considers the users as well as the capabilities and skills of the organisation in which the product is being developed (blue ring). On the product side this requires an understanding of many social science and humanities disciplines from the product aesthetics, drawing on art and applied arts, to user psychology. Management involves the allocation and control of human, financial and other resources to design artefacts then manufacture, operate, maintain and eventually dispose of them. What is managed, and how, is informed by the understanding of the artefact that is obtained through design. Resources are apportioned through management to achieve the best design outcomes, and this requires a deep understanding of the problem domain and of the opportunities for change. Product development can only be successful if it understands the wider social, political and economic context, which many products interact with in terms of regulatory requirements and constraints.

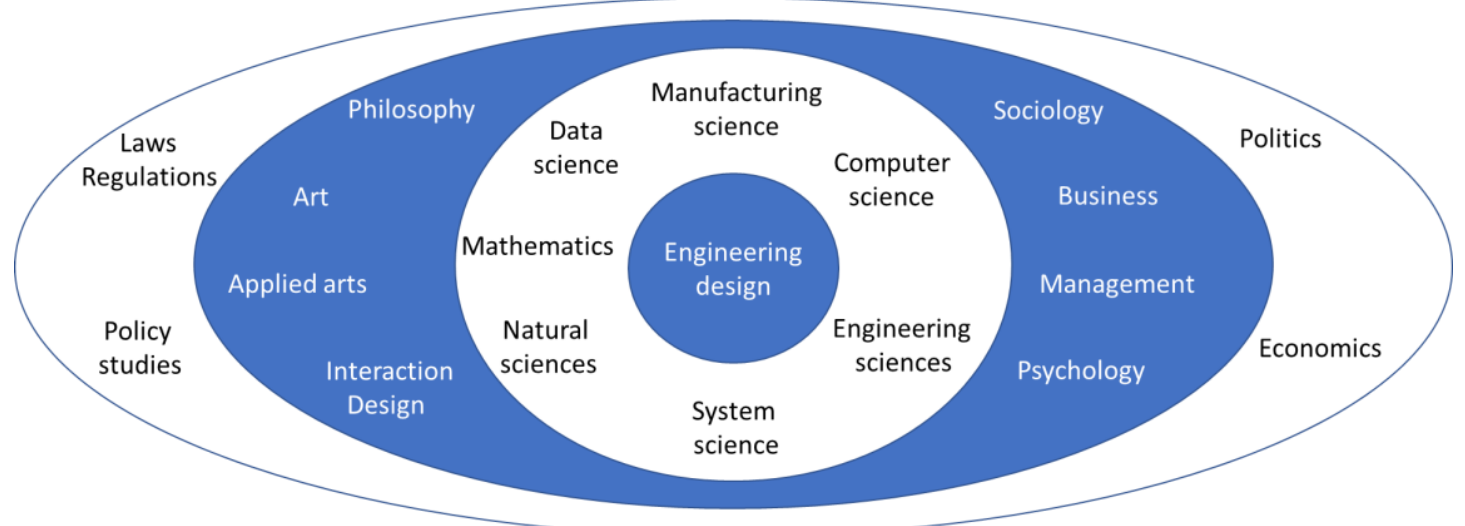

Figure 2. Engineering design in the context of other disciplines

\subsection{Design, science and technology}

Figure 2 shows engineering design drawing on many different sciences and their associated technologies. At present, is there also a gap in understanding the relationship between engineering design and technology, and engineering design and science? In many of the engineering design situations listed in section 3.3, a central part of the design challenge is to understand the current 'stateof-the-art' of technologies in the relevant technical domain and to embed them in the designed artefact, or to create a new technology through combination of existing technologies, or to create a new technology through exploitation of some newly discovered natural phenomenon. The interplay of design and technology implies a need to have a closer exchange with researchers in management, especially technology and innovation management, as well as the engineers who are developing new technologies themselves.

Outside of the engineering sciences and engineering design, engineering design is often seen simply as 'the appliance of science' or sometimes a rather 'fluffy, soft' subject compared with the 'hard' sciences. Nothing should be further from the truth. Engineering science helps in understanding and exploiting the phenomena on which technologies are based, but engineering design gives an understanding of how such technologies may be used in useful ways, and it is the process whereby the technological elements of artefacts are devised and then there is learning about the ways in which they may be developed and used. Furthermore, engineering design is integrative - it allows the knowledge of the different engineers and other specialists to be brought together. Design fosters understanding of constraints and exploration of trade-offs, but it also tells us where scientific effort or experiment is needed, where a constraint or requirement is not understood fully or where existing understanding may be embedded in tools that allow it to be exploited in the design process (McMahon 2021). Furthermore, while understanding the specific technologies involved in an artefact may be the province of technical specialists and managers, engineering design gives insight into the general opportunities for change through such approaches as product architecture, design-for- $\mathrm{X}$ and so on.

Design and technology also have a close interaction with the sciences that give us an understanding of the natural world. Science educator Olson, in a critique of the teaching of engineering and technology, argues that "the distinction between 'the natural world' and 'the human-built world' is a myth ... the two 
are inextricably intertwined" (Olson 2013). She notes that all technologies have unavoidable and often long-term consequences that cannot be simply designed away, including the effects of technologies on how designers think and act. The benefits and harms of technology and engineering are inequitably distributed, reflecting value systems often "biased toward positive perspectives of technology while downplaying or ignoring other important considerations". Olson's arguments emphasise the importance of the human and earth sciences in engineering design education and practice in the 21 st century.

The relationship and boundary between design and technology is, we believe, one of the critical issues for discussion by the community. Figure 3 shows a common view of the temporal evolution from the natural sciences to technology, to engineering science to design and design science. In this view, science yields a basic understanding of the world. This understanding gets translated into technology, which is developed until a proof of concept is possible. At this point new technology reaches a Technology Readiness Level 1 (Mankins 1995). This goes through significant engineering effort until it is sufficiently reliable and tested to be used in actual products. A specific product typically combines many different technologies, that are based on different scientific discoveries and engineering practices. Should we see engineering design as the step that brings in an understanding of the user and different contexts of use, drawing together technologies into an artefact, informed by the engineering sciences? Or should we see engineering design as extending to the left of the diagram, to include also the insights that recognise how a natural phenomenon might be used in a useful technology, or how multiple technologies might be brought together into a new technology? While often not recognised in public discourse, a great deal of development effort lies between basic technology development and market introduction and this depends heavily on the skills of engineering designers.

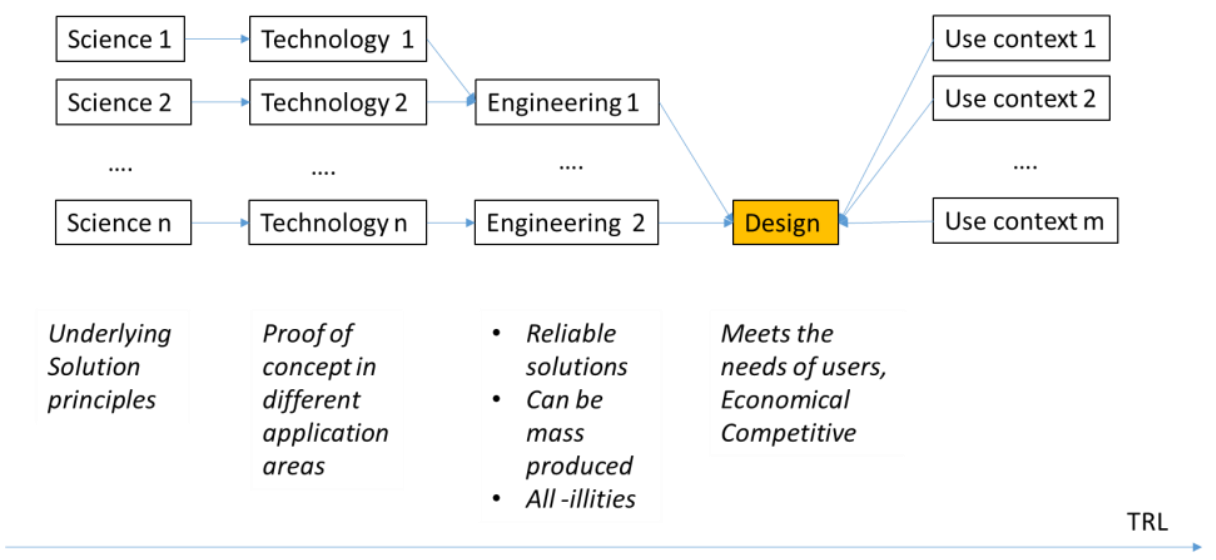

Figure 3. The evolution from science to design

Many engineering design researchers focus on a specific topic and develop it in more depth. This is certainly helpful for the whole field of design and should be further supported as long as the researchers specifically place their research within the overall domain of engineering design, highlighting their contributions but also the ranges of applicability of their approaches. But, how does the positioning described above enable engineering design researchers to consider the various situations described in section 3 more holistically? Researchers should use this positioning to identify problems that span disciplines and domains, scales and complexities, and identify the appropriate approaches, theories, and especially lacunas that would help to bridge the various situations and eventually help to holistically define the discipline of engineering design.

\section{CONCLUDING REMARKS}

Engineering design has an enormously important role to play in the creation of the artificial world. This position paper has presented the view that a debate in the engineering design community on the nature and positioning of engineering design and design research may be timely. In particular, it has suggested that such a debate might address the following questions:

- Is the fundamental nature of engineering design sufficiently well understood and explained, and are appropriate research methods used to gain the required understanding?

- Are the available design theories and methods sufficiently rich to explain and support engineering design in all its guises? 
- Is the positioning of engineering design with respect to other disciplines sufficiently well understood and described to explain the role and motivations of engineering design research to the wider world and to position the topic with respect to other disciplines?

As a starting point for such a debate it is contended that, firstly, the incremental nature of engineering design has been under-emphasised, as have the impacts of recent developments such as in the data sciences; secondly, that there may be merit in seeking to collect examples of a wide range of situations found in engineering design, and to use such a collection as a basis for exploring how well engineering design is explained and supported, and, thirdly, that a repositioning of engineering design may be timely, reemphasising its relationship with diverse sciences and technologies and with the wider social and political context.

\section{REFERENCES}

Ahmed, S., Wallace, K. and Blessing, L. (2003), "Understanding the differences between how novice and experienced designers approach design tasks", Research in Engineering Design, Vol. 14 No.1 (1): pp.1-11. https://doi.org/10.1007/s00163-002-0023-z

Andreasen, M. (1994). "Modelling — the language of the designer", Journal of Engineering Design, Vol. 5 No. 2, pp. 103-115. https://doi.org/10.1080/09544829408907876

Andreasen, M., Howard, T. and Bruun, H. (2014), "Domain Theory, its models and concepts", In: Chakrabarti, A. and Blessing, L. (Eds), An Anthology of Theories and Models of Design, Springer, London, pp. 173-195. https://doi.org/10.1007/978-1-4471-6338-1_9

Arthur, W.B. (2009), The Nature of Technology: What It Is and How It Evolves, Simon \& Schuster, New York.

Badke-Schaub, P. and Frankenberger, E. (1999), "Analysis of design projects", Design Studies, Vol. 20 No. 5, pp. 465-480. https://doi.org/10.1016/S0142-694X(99)00017-4

Brown, T. (2008), "Design thinking", Harvard Business Review, Vol. 86 No. 6, pp. 84-92.

Bucciarelli, L. (1994), Designing Engineers, MIT Press, Cambridge, MA.

Constant, E. (1980), The Origins of the Turbojet Revolution, Johns Hopkins University Press, Baltimore.

Cross, N. (1982), "Designerly ways of knowing", Design Studies, Vol. 3 No. 4, pp. 221-22. https://doi.org/10.1016/0142-694X(82)90040-0

Temple, M. (2010), The Design Council Review, Department for Business, Innovation and Skills.

De Weck, O., Roos, D. and Magee, C. (2011), Engineering Systems: Meeting Human Needs in a Complex Technological World, MIT Press, Cambridge, MA.

Dym, C., Agogino, A., Eris, O., Frey, D. and Leifer, L. (2005), "Engineering design thinking, teaching, and learning", Journal of Engineering Education, Vol. 94 No. 1, pp. 103-120. https://doi.org/10.1002/j.21689830.2005.tb00832.x

French, M. (1971), Conceptual Design for Engineers, Springer-Verlag, London.

Gericke, K., Eckert, C., Campean, F., Clarkson, P.J., Flening, E., Isaksson, O., Kipouros, T., Kokkolaras, M., Köhler, C., Panarotto, M. and Wilmsen, M. (2020), "Supporting designers: moving from method menagerie to method ecosystem". Design Science, Vol. 6, https://doi.org/10.1017/dsj.2020.21

Hatchuel, A. and Weil, B. (2003), "A new approach of innovative design: an introduction to CK theory", DS 31: Proceedings of ICED 03, the 14th International Conference on Engineering Design, Stockholm, August 1921, 2003, The Design Society.

Hatchuel, A., and Benoit W. (2009), "CK design theory: an advanced formulation", Research in Engineering Design, Vol. 19 No. 4, pp. 181-192. https://doi.org/10.1007/s00163-008-0043-4

Hazelrigg, G. (1998). “A framework for decision-based engineering design”, Journal of Mechanical Design, Vol. 120, pp. 653-658. https://doi.org/10.1115/1.2829328

Hughes, T. (1993), Networks of Power: Electrification in Western Society, 1880-1930, John Hopkins University Press, Baltimore.

Kuhn, T. (1962), The Structure of Scientific Revolutions, The University of Chicago Press, Chicago.

Maister, D. (1993), Managing the Professional Service Firm, Simon and Schuster, New York.

Mankins, J. (1995), Technology Readiness Levels: A White Paper, Office of Space Access and Technology, NASA.

McMahon, C. (2021), "Situations, patterns, exploration and exploitation in engineering design", She Ji: The Journal of Design, Economics, and Innovation, Vol. 6 No. 4.

Olson, J. (2013), "The purposes of schooling and the nature of technology: the end of education?" In: Clough, M., Olson, J. and Niederhauser, D. (Eds), The Nature of Technology, Brill Sense, Boston, pp. 217-248.

Pahl, G. and Beitz, W. (1984), Engineering Design: A Systematic Approach, Springer, Berlin.

Pugh, S. (1991), Total Design: Integrated Methods for Successful Product Engineering, Addison-Wesley, Wokingham.

Shigley, J. (1963), Mechanical Engineering Design, McGraw-Hill, New York.

Simon, H. (1996), The Sciences of the Artificial, 3rd edition, MIT Press, Cambridge, MA 